\title{
COกE)-(OES
}

CIÊNCIA E TECNOLOGIA

\section{COMPETÊNCIAS ESSENCIAIS EM ORGANIZAÇÃO DE PEQUENO PORTE: ESTUDO DE CASO EM EMPRESA DO SEGMENTO ALIMENTÍCIO NO MUNICÍPIO DE SANTA HELENA DE GOIÁS}

\author{
Maria Gláucia Dourado Furquim, José Carlos de Sousa Júnior, Daniela Cabral de Oliveira \\ Instituto Federal de Educação, Ciência e Tecnologia Goiano \\ <maria.furquim@ifgoiano.edu.br>. <josecarlos.junior@ifgoiano.edu.br>, <danielacaboliveira@gmail.com> \\ 10.21439/conexoes.v15i0.2111
}

\begin{abstract}
Resumo. A análise das competências essenciais possibilita definir um foco e direcionar esforços em tarefas específicas que geram vantagens competitivas, agreguem valor e proporcionam o crescimento da empresa dentro de parâmetros difíceis de serem copiados pelos concorrentes. O destino das organizações será definido com base em conceitos e valores estabelecidos por elas, dado o reconhecimento e a valorização das competências essenciais, influenciando nas mudanças de paradigmas e na evolução da sociedade empresarial. Dessa forma, compreender as competências essenciais consiste em conhecer melhor a própria organização, seus pontos fortes e, principalmente, identificar os diferenciais da empresa. A partir daí, será possível definir estratégias de gestão que potencializam a capacidade competitiva de acordo com as necessidades do mercado. Toda empresa possui características que a diferem das demais, são detalhes que influenciam o consumidor no momento de escolher determinada organização em comparação a outras do mesmo segmento. Assim, são justamente os conceitos desses "detalhes" que serão apresentados neste trabalho, verificados em uma microempresa por meio de pesquisa de campo e aplicação de 40 questionários a clientes, partindo da hipótese de que essas competências essenciais são responsáveis pelos bons resultados e pela sobrevivência dos negócios. Concluiu-se que a empresa possui vantagens competitivas, mas não competências essenciais.
\end{abstract}

Palavras-chaves: Competências essenciais. Mudanças de paradigmas. Vantagens competitivas.

\section{ESSENTIAL COMPETENCIES IN SMAL-HOLDER ORGANIZATIONS: A CASE STUDY FROM A FOOD COMPANY IN SANTA HELENA DE GOIÁS}

\begin{abstract}
Analyzing essential competencies allow defining focus and directing efforts in specific tasks that spawn competitive advantages, add value to the company and provide growing to it within guidelines that are difficult to be copied by its competitors. The future of organizations will be shaped based in values and concepts stablished by themselves, given the recognition and appreciation of the essential competencies that affect paradigm shift and business corporation evolution. In that way, the essential competencies understanding involve knowing their own organization better, including its strengths, and mostly, identifying the company's differential advantages. Thenceforth, management strategy definition will be possible so the competitive capacities are enhanced according to the market's needs. Every company has differential advantages that distinguish them from the others, they are the details that influence the costumers while choosing certain organization instead of another one from the same segments. Therefore, it is precisely those details' concepts that will be discussed in this study. They were checked in a small-business company through field research and forty surveys given to the costumers, stemming from the hypotheses that those essential competencies are the reason for the business good results and survival. This study's results showed that the researched company has competitive advantages, but not the essential competencies.
\end{abstract}

Keywords: Essential competencies. Paradigm shift. Competitive advantages.

\section{INTRODUÇÃO}

$\mathrm{O}$ acelerado ritmo de mudanças em todo o mundo tem reformulado a maneira de administrar as empresas, exigindo rápida adaptação aos mercados e inse- rindo diferenciais competitivos em todas as atividades. É crucial que os indivíduos conheçam suas competências pessoais nas três dimensões (conhecimentos, habilidades e atitudes) e a relação de interdependência entre elas. Dessa forma, estabelece-se um foco na definição 

ALIMENTÍCIO NO MUNICÍPIO DE SANTA HELENA DE GOIÁS

de competências essenciais nas instâncias organizacionais, buscando um equilíbrio entre o que a empresa almeja e o que o indivíduo mobiliza em face de uma situação profissional.

Pretendeu-se levantar, neste artigo, como identificar as competências essenciais de uma organização e como utilizá-las para obter vantagens competitivas, ou seja, quais são os recursos e as capacidades exclusivos de uma empresa em relação às suas rivais, que lhes garantem não apenas vantagens competitivas, mas, também, criação de valor e retornos acima da média.

Portanto, estima-se, com o término da pesquisa, comprovar a hipótese de que as competências essenciais são capacidades únicas de cada empresa, que servem de base para implantar suas estratégias com o desenvolvimento de novas oportunidades de negócios.

Outra hipótese que pretendeu confirmar é a utilização desses conceitos no contexto das pessoas, uma vez que as competências essenciais proporcionam um direcionamento profissional, alocando o indivíduo de acordo com as suas capacidades técnicas e humanas.

Objetiva-se, logo, compreender os critérios necessários para identificar as competências essenciais numa empresa e, com posse desses dados, definir estratégias práticas de gestão que visem à máxima utilização das competências em prol dos objetivos da empresa, ou seja, explorando o que ela possui de melhor. Segundo Barreto, Nóbrega e Araújo (2020, p. 37) “É importante evidenciar que muitas empresas sentem dificuldades em saber quando uma competência é essencial ou não".

Como exemplo, analisa-se uma microempresa do segmento alimentício, em Santa Helena de Goiás, verificando, na prática, se os empresários sabem identificar seus diferenciais e gerir eficientemente seu negócio, não sendo apenas mais uma no mercado à mercê dos obstáculos apresentados pelo ambiente interno e externo. A escolha ocorreu pela disponibilidade dos proprietários em participar da pesquisa, bem como do pioneirismo dos mesmos em comercializar os produtos de forma diferenciada.

Nesse contexto, justifica-se efetuar este estudo pela necessidade premente de conhecer as melhores práticas aplicadas à gestão de uma empresa para a descoberta de suas competências essenciais e, consequente, obtenção de vantagens sustentáveis.

\section{REVISÃO TEÓRICA}

\subsection{Conceito sobre "Competências"}

De acordo com Hitt, Ireland e Hosrisson (2002), a estratégia empresarial é o caminho traçado, o plano de ação para se chegar aos objetivos da empresa, levando em consideração seus recursos, suas competências essenciais, seu conhecimento do mercado, entre outros fatores determinantes na complexidade de uma estrutura organizacional. Segundo os autores, uma empresa possui uma vantagem competitiva sustentável quando consegue implantar uma estratégia que agregue valor social e econômico. Para que isso ocorra, é necessário combinar, de maneira eficiente, seus recursos, suas capacidades e suas competências essenciais.

Os recursos de uma empresa podem ser definidos como todos os bens tangíveis (recursos físicos ou materiais) e intangíveis (são os recursos intelectuais, de inovação, de confiabilidade e demais aspectos que não constam nos demonstrativos financeiros de uma empresa) que ela possui ou utiliza como fatores de produção, sendo o objetivo de toda organização gerir com eficiência e eficácia os seus fatores produtivos.

Quando se combinam os recursos, obtêm-se as capacidades, ou seja, as atividades que a empresa realiza com qualidade e que a diferenciam de seus rivais. As capacidades estão baseadas no conhecimento organizacional e no uso estratégico dos recursos. Contudo, mais do que administrar os recursos da empresa ou definir quais são suas capacidades, as organizações de sucesso estão combinando os recursos com as suas capacidades peculiares da organização, identificando quais são seus elementos escassos, valiosos e difíceis de imitar que constituem as competências essenciais da instituição (ZABOTTO; ALVES, 2019). Conforme Fleury e Fleury (2000), nas esferas acadêmica e empresarial o tema competência tem adquirido maior visibilidade, bem como suas distintas instâncias de compreensão “[...] no nível da pessoa (a competência do indivíduo) das organizações (as core competences) e dos países (sistema organizacional e formação de competências)" (FLEURY; FLEURY, 2000, p. 62).

No âmbito da gestão de pessoas, a competência é definida como a forma diferenciada com que o indivíduo desenvolve determinada função na empresa. No aspecto empresarial, refere-se a um novo conceito de competição pelo futuro, em que a empresa busca, internamente, fatores que possibilitam vantagens futuras e a tornem única. Neste sentido, o desenvolvimento de competências essenciais decorre da sinergia entre a reunião adequada dos recursos (tangíveis e intangíveis) associada à capacidade da empresa de empregar esses recursos para alcançar a posição desejada. Segundo Tomomitsu, Carvalho e Moraes (2017, p. 359), "Deve-se entender as competências como capacidades que uma organização possui e que podem determinar o sucesso em termos de competitividade das empresas".

Observa-se, portanto, que os aspectos organizacio- 

ALIMENTÍCIO NO MUNICÍPIO DE SANTA HELENA DE GOIÁS

nais em sua amplitude devem ser considerados no construto como competências essenciais, contemplando as áreas de recursos humanos, produção, finanças, entre outros, referendando que em todas as atividades de uma empresa existem pessoas envolvidas. Conforme Hamel e Prahalad (2005, p. 151), “a intenção estratégica deve ser o objetivo que comanda o respeito e o compromisso de cada funcionário. O destino não precisa ser só diferente, precisa também valer a pena”. O colaborador precisa ser visto pela direção como parte integrante da empresa, que contribui para a construção de um legado. São cérebros, mas, especialmente, corações que estão empregando suas capacidades físicas e emocionais em prol da empresa.

Ao longo da história, foram adotadas várias definições para o indivíduo enquanto colaborador. Na época da Revolução Industrial, o funcionário era tido como um mero recurso para a obtenção de resultados, sendo comparado a uma máquina. No Período Neoclássico, surgiram diversas teorias administrativas sobre os modelos de gestão, apresentando uma abordagem sobre o comportamento humano e demonstrando como o indivíduo é importante para o alcance dos objetivos organizacionais. Com a Era da Informação, intensifica-se a competitividade entre as organizações, dada a democratização da informação e a globalização da economia e do conhecimento, forçando as empresas a estabelecerem novos conceitos sobre a Gestão de Pessoas. Atualmente, na Era do Capital Intelectual, as organizações investem em pessoas, buscando manter equipes de alta performance, pois reconhecem que as metas serão alcançadas por meio delas.

De acordo com Chiavenato (2009), o capital humano refere-se às pessoas que compõem a organização "Esse capital pode valer mais ou valer menos na medida em que contenha talentos e competências capazes de agregar valor à organização e torná-la mais ágil e competitiva" (CHIAVENATO, 2009, p. 173).

Assim, inúmeras mudanças ocorreram na área de gestão de pessoas no cenário mundial, reforçando a transformação da informação em conhecimento e esses conhecimentos, combinados com as habilidades individuais, geram as competências profissionais.

Desta forma, os colaboradores estão se preparando para exercer com eficácia as tarefas que lhes são designadas, uma vez que as organizações têm exigido indivíduos cada vez mais dinâmicos e que superem as expectativas. Por sua vez, os colaboradores estão buscando um conjunto de condições diferentes da estabilidade e do plano de benefícios convencionais; querem melhores condições de trabalho, onde possam desempenhar bem suas competências, planejarem uma carreira, dando abertura para que eles diferenciem positivamente a empresa em seu mercado.

É necessário que haja conexão entre as competências essenciais organizacionais com as competências individuais, fazendo com que elas se desenvolvam juntas. Conforme Dutra, Fleury e Ruas (2008), existem diferentes aspectos da gestão de pessoas que abordam as competências profissionais, entre eles (Tabela 1 ).

De acordo com (DUTRA; FLEURY; RUAS, 2008. p. 25), "a consolidação da noção de competência inicia pela transição do conceito de qualificação para o de competência, período em que a ênfase principal é a identificação das capacidades necessárias para atuar em certo tipo de tarefa e obter um desempenho superior".

Inicia-se um período em que a competência é posta em xeque, ou seja, ela pode ser mobilizada na prática para a obtenção de benefícios frente a um mercado repleto de novos elementos de instabilidade e de flexibilidade. As competências não são meros acessórios aos profissionais, mas uma exigência das organizações para transformar ações em resultados, uma vez que possibilita “[...] estabelecer relações entre a estratégia, as funções críticas, as competências essenciais da organização e as competências individuais. Esse alinhamento entre a estratégia e as competências torna a empresa mais homogênea em seus objetivos presentes e futuros" (BRIDA; SANTOS, 2011, p. 211).

\subsection{Conceito de competência para o profissional}

O conceito de competência para o indivíduo consiste em transformar suas capacidades técnicas e humanas para atender aos requisitos estabelecidos pelo mercado de trabalho global. É uma busca pela interação entre o que se deseja na esfera organizacional e o que se tem no âmbito intelectual. É importante que o colaborador tenha consciência de suas potencialidades e dos seus pontos fracos a serem trabalhados, pois não é suficiente apenas saber algo, mas sim ser competente naquilo que se faz.

Atualmente, as empresas têm adotado, além das técnicas tradicionais de seleção de pessoal, o modelo de seleção por competência, que abrange, além dos aspectos técnicos, os fatores relacionados às habilidades que um indivíduo possui ou pode adquirir e sua postura para apresentar melhor desempenho no cargo. O conjunto de competências individuais que os profissionais disputados pelas organizações possuem é identificado pela expressão CHA, ou seja, conhecimentos, habilidades e atitudes, estabelecendo a maneira como essas características individuais são mobilizadas para oferecer resultados concretos às empresas (Figura 1 . 
Tabela 1: Relação entre competências essenciais organizacional e individual

\begin{tabular}{|c|c|}
\hline Aspectos da gestão de pessoas & Competências profissionais relacionadas \\
\hline $\begin{array}{l}\text { Mapeamento de competências } \\
\text { individuais e/ou gerenciais }\end{array}$ & $\begin{array}{l}\text { Consiste em identificar as competências necessárias } \\
\text { a funções específicas, adequando essas características } \\
\text { às perspectivas de novas situações de trabalho. É uma } \\
\text { abordagem que foca nos resultados, por estabelecer } \\
\text { previamente quais os métodos mais propícios para } \\
\text { cada ambiente. }\end{array}$ \\
\hline $\begin{array}{l}\text { Formação e desenvolvimento } \\
\text { de competências }\end{array}$ & $\begin{array}{l}\text { Um dos grandes dilemas das empresas atuais consiste, } \\
\text { justamente, em formar e desenvolver competências } \\
\text { profissionais em um cenário empresarial de constantes } \\
\text { mutações, no qual os treinamentos convencionais não } \\
\text { preparam para a formação de capacidades que sejam } \\
\text { utilizadas em médio prazo. }\end{array}$ \\
\hline Remuneração por competências & $\begin{array}{l}\text { A remuneração é o principal fator de gestão e de retenção } \\
\text { de recursos humanos, contudo, a incorporação de } \\
\text { benefícios serviu de incentivo para manter o colaborador } \\
\text { e de estímulo para o alcance das metas de trabalhos } \\
\text { individuais, bem como da equipe. Deve, porém, ater-se } \\
\text { para que a sobrecarga de trabalho e de controles não crie } \\
\text { um clima de tensão ou competição entre os gestores. }\end{array}$ \\
\hline $\begin{array}{l}\text { Acerca do conceito de } \\
\text { competências profissionais }\end{array}$ & $\begin{array}{l}\text { A análise das competências individuais busca abordar } \\
\text { as capacidades que o colaborador dispensa ao } \\
\text { ambiente de trabalho para alcançar os interesses } \\
\text { econômicos da empresa. }\end{array}$ \\
\hline
\end{tabular}

Figura 1: Competência como fonte de valor para o indivíduo e para a organização.

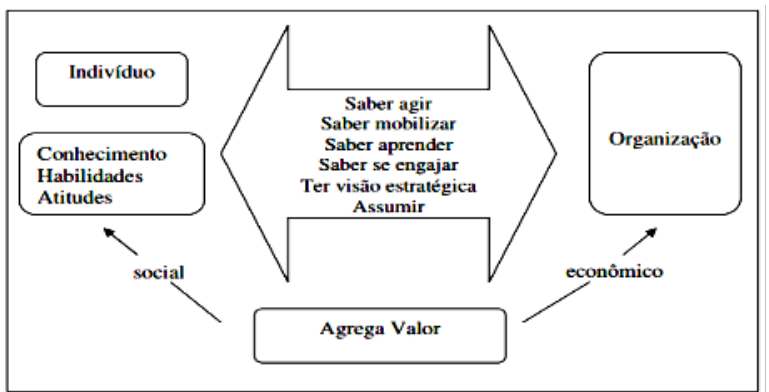

Fonte: Fleury e Fleury (2001 p. 188).

A melhoria contínua dos profissionais e dos processos vem ocasionando profundas mudanças nas organizações, pois os colaboradores alcançaram um papel estratégico nas empresas e a máxima utilização das competências influencia positivamente suas cadeias de valores. Segundo Fleury e Fleury (2000, p. 68), “a competência é a inteligência prática de situações que se apoiam sobre conhecimentos adquiridos e os transformam com quanto mais força, quanto mais aumenta a complexidade das situações".

O profissional que desenvolve competências consegue gerir sua carreira de maneira diferenciada, pois agrega, ao seu perfil, comportamentos que lhe possibilitam um melhor desempenho em qualquer situação, uma vez que consegue estabelecer uma interação entre as dimensões que constituem suas competências (conhecimento, habilidades e atitudes). Complementarmente, Gontijo et al. (2013, p. 528) apontam que "Não é apenas a posse de conhecimentos que avaliza a competência, mas o uso que se é capaz de fazer dos conhecimentos frente a situações que fogem à regra. Diz respeito ao modo como se utilizam, integram e mobilizam conhecimentos".

A competência, portanto, não se restringe a uma quantidade de conhecimentos, mas a como utilizá-los de forma prática no contexto organizacional, agregando valor econômico para a organização e valor social para o indivíduo. As competências de cada pessoa só trarão benefícios reais se oferecerem resultados satisfatórios e superiores para o colaborador e para a empresa. 


\subsection{Noções de competências de uma organização}

Com base na sociedade empresarial atual, desenvolveu-se um novo conceito de competição pelo futuro, que garanta à instituição uma sustentável vantagem frente aos seus rivais e que gere lucros e oportunidades. Surgem as core competences, ou seja, competências essenciais que objetivam possibilitar a obtenção de benefícios reais às empresas, por meio da potencialização de suas capacidades únicas e estratégicas. De acordo com Vasconcelos et al. (2015, p. 912), a incorporação de mudanças na estrutura organizacional decorre de pressões ambientais "As mudanças ambientais costumam exigir que as organizações renovem, de forma constante, seu portfólio de recursos e competências, de forma a garantir sua sobrevivência e um desempenho econômico diferenciado das demais empresas".

Para Hamel e Prahalad (2005, p. 230), "as competências essenciais são a fonte de desenvolvimento de futuros produtos, são as raízes da competitividade e os produtos e serviços, são seus frutos". Vemos que o conceito de competência está diretamente relacionado às transformações no ambiente de negócios e nos impactos causados no novo ambiente. Contudo, competências essenciais não se resumem a produtos ou serviços simplesmente, e sim ao caminho que contribui para o crescimento da empresa, dados os produtos ou serviços que ela oferece. Por sua vez, Dutra, Fleury e Ruas (2008. p. 12) sugerem que o entendimento acerca de competências essenciais serve para referenciar diferentes responsabilidades e contribuições individuais no ambiente interno da empresa, fruto do foco no desempenho, na mobilização contextualizada e na contribuição do trabalho para a estratégia empresarial.

Por isso, a necessidade de as empresas terem em suas equipes líderes que estimulem o desenvolvimento das competências essenciais na organização, a fim de obter sucesso competitivo.

\subsection{0 que é competência essencial versus o que não é competência essencial}

Quando se fala em competências ou capacidades essenciais, um aspecto importante refere-se à forma como as empresas definem o que são "competências essenciais" das "não essenciais" da organização, ou seja, devese não apenas identificar as capacidades potencialmente importantes, mas, principalmente, estabelecer um foco, distinguindo as centrais das secundárias. Conforme esclarecem Hamel e Prahalad (2005), a empresa precisa distinguir claramente o que são competências específicas de vantagem competitiva para não incorrer no erro de ancorar-se em vantagem baseada em infraestrutura e reduzir os investimentos no desenvolvimento de competências verdadeiramente únicas.

Dessa forma, devem-se estabelecer parâmetros para diferenciar as competências essenciais dos demais fatores críticos de sucesso da empresa. Aspectos que possam oferecer vantagens a uma empresa em relação aos seus concorrentes como: licença de importação exclusiva de determinado produto, acordo de licenciamento a uma determinada tecnologia, fábricas instaladas próximo aos fornecedores de matéria-prima ou localizadas em um lugar com baixo custo de mão de obra são fatores críticos de sucesso e oferecem vantagens competitivas, mas não podem ser consideradas competências essenciais, pois esses elementos podem ser obtidos pelos concorrentes.

Uma competência é o conjunto de habilidades e aptidões, combinados de maneira única e refletindo a personalidade da empresa. Segundo Carletto, FRANCISCO e Kovaleski (2005, p. 5), “[o] estudo das competências essenciais permite a empresa definir o foco e concentrar esforços no desenvolvimento de tarefas que gerem vantagens competitivas, aglutinem valor e aumente a capacidade de expansão da organização com padrões de excelência". Sob esse prisma, a identificação e o desenvolvimento das competências essenciais deram-se em virtude da acirrada competição estabelecida pelas empresas em busca de posição e poder no mercado.

Surge, daí, a necessidade de definir quais são as capacidades efetivamente importantes na empresa e o direcionamento dos esforços nas competências que trarão retorno. De acordo com Hamel e Prahalad (2005), para que uma competência seja considerada essencial, ela deve atender a três requisitos básicos:

- Valor percebido pelo cliente - uma competência, para ser essencial precisa agregar valor econômico ao que a empresa oferece, dado o benefício adicional que proporciona ao cliente. Este, por sua vez, julga se uma competência é essencial ao identificar para a empresa quais são os elementos de valor que o produto ou serviço possui e porque pagam por ele.

- Diferenciação entre concorrentes - os concorrentes, assim como os clientes, são indicadores de que uma capacidade seja ou não essencial, pois ela precisa ser competitivamente única e difícil de imitar para propiciar diferenciação e vantagens em relação a seus rivais.

- Capacidade de expansão - uma competência essencial oferece à empresa a possibilidade de entrada em novos mercados de produtos ou serviços, 
ou seja, proporciona benefícios em curto e longo prazo.

Ainda segundo a definição de Hamel e Prahalad (2005, p. 241), "o que era uma competência essencial há uma década pode se transformar em uma mera capacidade na década seguinte". Sempre que uma organização realiza mudanças estruturais para eliminar defasagens, ela transforma algumas competências em vantagens comuns, já que essas mudanças não oferecem diferenciais e sim adequação ao mercado. Dessa maneira, isso ocorreu quando as empresas estabeleceram padrões de qualidade, quando surgiram as centrais de atendimento ao cliente e velocidade de chegada a novos mercados. Todos esses aspectos eram antes considerados verdadeiros diferenciais e estão se tornando vantagens habituais.

Uma competência essencial não é um "ativo" no sentido contábil da palavra. Ao contrário dos ativos físicos, as competências não sofrem "desgaste", embora uma competência essencial possa perder seu valor com o tempo. Em geral, quanto mais a competência é usada, mais aprimorada e valiosa ela se torna. Destarte, as competências essenciais consistem na habilidade da empresa de explorar suas capacidades e seus recursos tangíveis e intangíveis e de eles obterem lucros, enquanto os demais ativos físicos da empresa podem perder seu valor mediante as mudanças no mercado. Conforme esclarecem Barreto, Nóbrega e Araújo (2020 p. 39) "Desenvolver competências essenciais torna-se, portanto, um diferencial competitivo, geram valor distintivo e difícil de ser imitado promovendo uma vantagem competitiva, pois a atual conjuntura requer capacidades específicas para enfrentar o cenário competitivo no mercado".

\section{METODOLOGIA}

Este estudo consistiu no estudo de base teórica e de uma pesquisa in loco na empresa analisada, configurando em uma pesquisa exploratória através de um estudo de caso.

O estudo da teoria foi desenvolvido com a utilização de fontes diversas, tais como: livros, artigos científicos e periódicos pertinentes ao tema em locais diversos, inclusive na internet. As obras consultadas oportunizaram o levantamento de diversos conceitos sobre as ferramentas de gestão pesquisadas.

A pesquisa de campo foi desenvolvida com a aplicação de um questionário para a clientela do empreendimento estudado e a observação empírica do tipo de gestão aplicada ao negócio.
Essa abordagem proporcionou melhor entendimento das questões observadas no estudo teórico e das constatadas na prática.

Como instrumento metodológico, utilizou-se se questionário aberto, contendo 5 questões que foram aplicados a 40 clientes distintos no decorrer de um mês, sendo os mesmos entregues aos clientes no ato do atendimento pelos garçons, em mesas com mais de três clientes, para que eles pudessem refletir sobre as questões e responder o questionário enquanto os produtos estivessem sendo preparados. Buscou-se, então, definir quais aspectos diferenciam a empresa, em sua percepção, em relação aos concorrentes do mesmo segmento, comparando as respostas dos clientes com as características apontadas pelos proprietários, por meio de uma entrevista semiestruturada, com os mesmos quesitos a serem analisados pelos clientes. O emprego do método quali-quantitativo objetivou identificar a existência de acontecimentos e esclarecer fatos alinhados à teoria abordada, associados à mensuração dos resultados obtidos.

\section{RESULTADOS E DISCUSSÕES}

\subsection{Análise dos dados da pesquisa}

A identificação das competências essenciais nas organizações é uma atividade que transcende o porte das empresas. Em função disso, foi realizada uma pesquisa de campo, abrangendo uma microempresa, situada no município de Santa Helena de Goiás, procurando conhecer acerca dos impactos das competências na esfera organizacional e quais os benefícios obtidos com a gestão dessas competências.

A empresa pesquisada está no mercado desde 2004 e atua no segmento alimentício (sorveteria), tendo, inicialmente, uma única atividade comercial, a venda de sorvete em bola e taças ornamentadas. Posteriormente, passou a comercializar também caldos de frango, feijão, misto e outros para complementar o faturamento, uma vez que a demanda de sorvete é muito sazonal. Nesse sentido, posicionaram-se conforme sintetizado na Tabela2

Após a apuração da visão dos proprietários da empresa, foram analisadas as respostas dadas no questionário aplicado aos clientes, para estabelecer parâmetros que pudessem identificar as competências essenciais da empresa.

A primeira pergunta feita aos clientes objetivou verificar seu grau de fidelização, sendo questionado há quanto tempo é cliente e com qual constância frequenta o estabelecimento.

A Figura 2 - Tempo de frequência ao estabeleci- 
Tabela 2: Aspectos positivos e negativos presentes no ambiente interno.

\begin{tabular}{ll}
\hline \multicolumn{1}{c|}{ Pontos Fortes } & \multicolumn{1}{c}{ Pontos Fracos } \\
\hline Produtos de qualidade; & Infraestrutura; \\
Parceria com empresa conceituada no mercado de sorvete; & Atendimento ao cliente; \\
Preço; & Grande número de concorrentes; \\
Produtos diferenciados; & Estoque pequeno; \\
Localização; & Baixo capital de giro; \\
Ambiente agradável. & Funcionários desmotivados. \\
\hline
\end{tabular}

Figura 2: Tempo de frequência ao estabelecimento comercial.

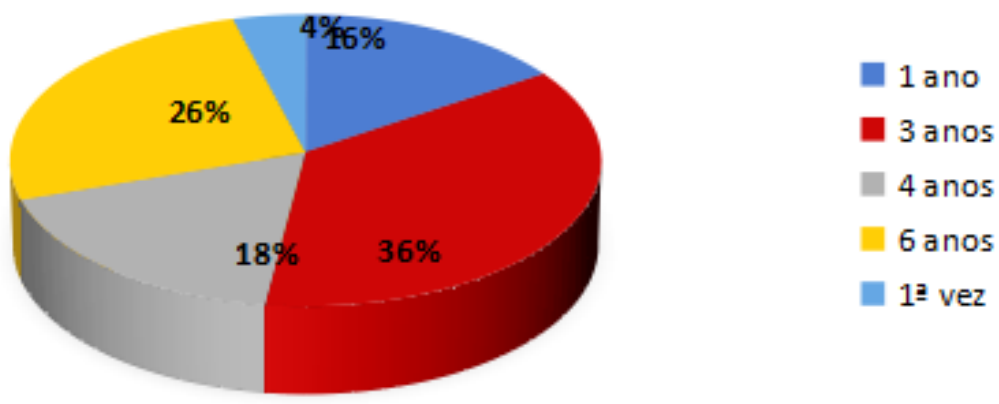

mento comercial - mostra que a maioria dos clientes pesquisados, $36 \%$, frequentam a empresa há 3 anos, $26 \%$ há 6 anos, $18 \%$ há 4 anos, $16 \%$ há 1 ano e $4 \%$ foram pela primeira vez. Com base nesses resultados, constatou-se que um dos gargalos da empresa é atrair novos clientes, uma vez que o menor índice de respostas foi dado por novos clientes. Em contrapartida, verificou-se um significativo grau de fidelização dos clientes, pois pelo menos oitenta por cento $(80 \%)$ deles frequentam a empresa há pelo menos 3 anos. Destes, mais de um quarto $(1 / 4)$ dos pesquisados é cliente há 6 anos e a empresa analisada está no mercado há 7 anos.

A segunda pergunta respondida pelos clientes, como denota a Figura 3, retrata qual o produto mais consumido, bem como a proporção de consumo dos itens comercializados.

Assim, o sorvete em taças é responsável por $48 \%$, os caldos (frango, feijão, vatapá e chica doida) por $44 \%$ e o açaí por $8 \%$ das vendas, sendo estes os únicos itens produzidos. Esses resultados sugerem que, embora a empresa seja uma sorveteria, esta não é mais a sua atividade principal, pois a venda de caldos e de açaí atinge $52 \%$ do faturamento, além de ser menos sazonal. Em adição, conforme os proprietários, a venda desses produtos é mais rentável por não haver exclusividade de fornecedor, possibilitando mais poder de barganha na hora de adquirir as matérias-primas, ao contrário do sorvete, que não é fabricado pela empresa e, para ser revendido, é necessária a obediência aos parâmetros estabe- lecidos pelo fornecedor, como exclusividade de marca e preço de venda.

$\mathrm{Na}$ terceira pergunta foi questionado aos clientes o que eles consideram como diferencial da empresa em relação às do mesmo segmento.

De acordo com o demonstrado na Figura 4- Diferencial da empresa em relação a outras do segmento, $40 \%$ responderam que optam pela empresa devido à forma variada de servir o sorvete (taças ornamentadas), $38 \%$ pela qualidade do caldo, $14 \%$ pelo atendimento e $8 \%$ pela localização. Essa pergunta objetivou identificar o que a empresa tem de atrativo e que faz com que o cliente a escolha, ou seja, o que ela possui que as demais concorrentes não têm e que não pode ser copiado, que corresponderia a sua competência essencial. As respostas obtidas, além da localização, que apresenta o menor quantitativo de escolhas, sugerem que a empresa não possui nenhuma característica que seja exclusiva, que não pode ser copiada pelos concorrentes e que influencia seus clientes no momento de escolher a empresa em relação aos concorrentes, ou seja, não possui competências essenciais definidas.

A quarta questão buscou identificar quais são as áreas que requerem cuidados na empresa e que precisam ser melhoradas.

A Figura 5 apresenta o que precisa ser melhorado - evidenciando que $40 \%$ dos clientes requerem melhorias em infraestrutura (ampliando o estabelecimento, tornando-o mais arejado e com mesas e cadeiras mais 


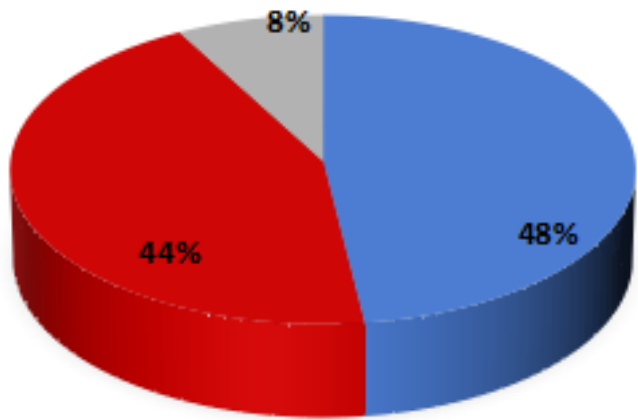

Sorvete

- Caldo

Açaí

Figura 4: Diferencial da empresa em relação a outras do mesmo segmento.

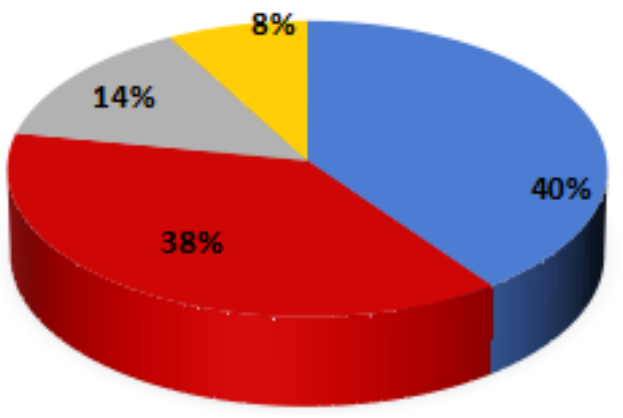

Variedade de taças

Qualidade do caldo

Atendimento

Localização

Figura 5: O que precisa ser melhorado.

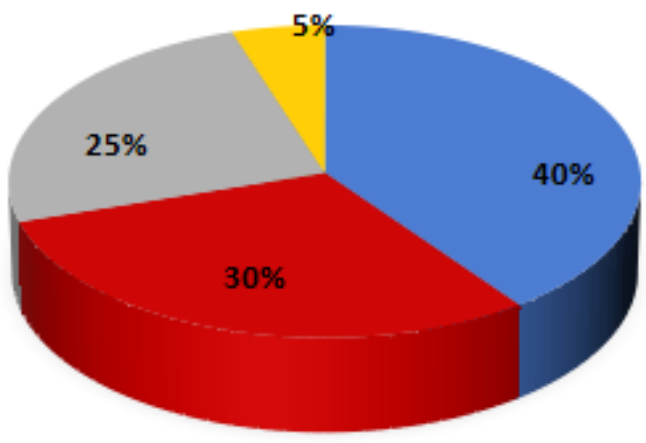

Infraestrutura

Atendimento

Agilidade

Variedade de Produtos aconchegantes), 30\% reclamam do atendimento, solicitando um maior número e melhor capacitação de funcionários, $25 \%$ solicitam agilidade da equipe de trabalho, para que diminua o tempo entre a realização do pedido e a sua entrega e apenas $5 \%$ querem mais variedade de produtos (mais opções de sabores de sorvete, recheios e mais variedade de caldos).

Com base nos dados obtidos, verificou-se que, embora $40 \%$ das queixas se refiram a questões estruturais (adequações no ambiente), mais de $55 \%$ apontam a necessidade de melhorias na equipe de trabalho, com pessoas bem treinadas e que desempenham melhor suas funções. Em decorrência disso, foram contratados dois funcionários (diaristas) para trabalhar nos dias de mais demanda (sexta, sábado e domingo), proporcionando mais agilidade e aumento no número de clientes atendidos. Com isso, buscou-se alinhar as pessoas e seu desempenho às estratégias do negócio e às condições de seus gestores.

A quinta questão procurou explorar a opinião dos clientes sobre o que deve ser preservado.

Nessa questão, como é visível na Figura 6- O que o cliente considera que deve ser preservado, os clientes consideram o quesito qualidade, com $90 \%$ das respostas, sendo a principal característica a ser preservada. Dez por cento (10\%) escolheram o preço nesse quesito. 


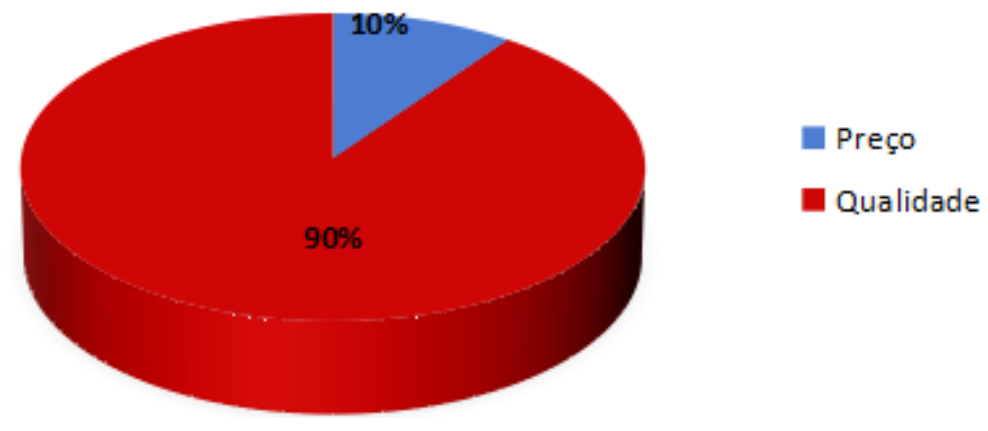

$\mathrm{O}$ fato de os clientes terem mencionado apenas duas características a serem conservadas só reforça os pontos fracos da empresa já destacados.

O estudo teórico propõe que a competência essencial, mais do que uma ferramenta para a competitividade de qualquer organização, é considerada um novo modelo de gestão que visa a proporcionar crescimento, direcionando esforços em áreas específicas. Ressaltase que toda organização possui características únicas, percebidas pelos clientes, diferenciando-a das demais. Isso deve ser identificado, trabalhado e potencializado. A análise dos resultados da pesquisa de campo realizada sugere que a empresa estudada detém diferenciais competitivos, como a qualidade dos produtos, a maneira como as taças com sorvetes são servidas, entre outros. No entanto, praticamente todos esses diferenciais não se apresentam como competências essenciais, podendo, inclusive, o da localização ser copiado pela concorrência.

O fator qualidade dos produtos, por exemplo, é indispensável para a sobrevivência de qualquer empresa, não sendo, então, um diferencial, e sim uma necessidade.

A maneira como os sorvetes são servidos possivelmente pode vir a se tornar uma competência essencial, especialmente se a empresa investir no desenvolvimento das competências profissionais de seus colaboradores, que podem se estender para a competência empresarial, a qual possibilite uma posição privilegiada frente a suas concorrentes. Contudo, observa-se que a empresa não possui características que a torne única na percepção dos clientes no longo prazo e que dificilmente sejam reproduzidos pelos concorrentes. Neste sentido, faz-se necessário explorar os atributos que a diferencia dos concorrentes, ao mesmo tempo em que se busca minimizar as fragilidades pontuadas internamente.

\section{CONSIDERAÇÕES FINAIS}

O aumento da competitividade entre as empresas imputa a adoção de modelos de gestão que possibilita o alcance de melhores resultados associados a possibilidade de diferenciação frente aos principais concorrentes. Neste sentido, quando se trata de competências essenciais no âmbito das organizações, é necessário aprofundar o entendimento sobre as particularidades da empresa no sentido de identificar aquilo que a torna única aos olhos do cliente e que dificilmente pode ser copiado.

Sob essa ótica, a análise dos aspectos levantados na empresa em questão sugere que, embora a empresa apresente diferenciais competitivos, eles não configuram competências essenciais por não ser um atributo exclusivo da empresa, podendo ser facilmente "copiado" pelos concorrentes. Assim, os resultados da pesquisa contribuem para elucidar aspectos que, na prática do mercado, geram imprecisão como a distinção entre: vantagens competitivas, diferenciais competitivos e competências essenciais. Ao mesmo tempo, trazem um feedback importante aos proprietários do empreendimento que poderá direcionar esforços para áreas críticas dentro da organização, proporcionando uma tomada de decisão mais assertiva.

Ademais, pode-se confirmar a hipótese da importância estratégica do tema competências essenciais na esfera organizacional e profissional, conforme referencial teórico consultado, embora a temática apresente poucas publicações recentes com enfoque prático e específico sobre o assunto; sendo comumente abordada de forma associada ao planejamento estratégico, estratégia, percepção ambiental entre outros conceitos que limitam o aprofundamento e a compreensão acerca do que é competência essencial e qual a sua importância na condução de qualquer empreendimento atualmente evidenciando, assim, a atualidade e relevância do tema. 
COMPETÊNCIAS ESSENCIAIS EM ORGANIZAÇÃO DE PEQUENO PORTE: ESTUDO DE CASO EM EMPRESA DO SEGMENTO ALIMENTÍCIO NO MUNICÍPIO DE SANTA HELENA DE GOIÁS

REFERÊNCIAS

BARRETO, M. C.; NÓBREGA, K. C.; ARAÚJO, P. S. R. Competências essenciais como vantagem competitiva: o desafio das micro e pequenas empresas (MPE'S). Revista Eletrônica do Mestrado Profissional em Administração da UnP, v. 12, n. 1, p. 35-46, 2020.

BRIDA, M.; SANTOS, J. N. O alinhamento entre a estratégia e as competências organizacionais: $o$ caso de uma empresa nacional líder do segmento de revestimentos cerâmicos. Ciencias da Administraçao, Universidade Federal de Santa Catarina (UFSC), v. 13, n. 31, p. 210-242, 2011.

CARLETTO, B.; FRANCISCO, A. C. d.; KOVALESKI, J. L. Competências essenciais: contribuições para o aumento da competitividade. In: Anais do ADM 2005 - Congresso de Administração. Ponta Grossa: UEPG, 2005. v. 1, p. 1-8.

CHIAVENATO, I. Planejamento, recrutamento e seleção de pessoal: como agregar talentos à empresa. 1. ed. São Paulo: Manoele, 2009.

DUTRA, J. S.; FLEURY, M. T. L.; RUAS, R. L. Competências: Conceitos, métodos e experiências. 1. ed. São Paulo: Atlas, 2008. v. 1.303 p.

FLEURY, M. T. L.; FLEURY, A. Estratégias empresariais e formação de competências. 1. ed. São Paulo: Atlas, 2000.

Construindo o conceito de competência. Revista de administração contemporânea, SciELO Brasil, v. 5, n. 1, p. 183-196, 2001.

GONTIJO, E. D.; ALVIM, C.; MEGALE, L.; MELO, J. R. C.; LIMA, M. E. C. d. C. Matriz de competências essenciais para a formação e avaliação de desempenho de estudantes de medicina. Revista Brasileira de Educação Médica, SciELO Brasil, v. 37, n. 1, p. 526-539, 2013.

HAMEL, G.; PRAHALAD, C. K. Competindo pelo futuro: estratégias inovadoras para obter o controle do seu setor e criar os mercados de amanhã. 1. ed. Rio de Janeiro: Campos, 2005.

HITT, M. A.; IRELAND, D. R.; HOSRISSON, R. E. Administração estratégica. 1. ed. São Paulo: Thomson, 2002.

TOMOMITSU, H. T. A.; CARVALHO, M. M. d.; MORAES, R. d. O. The evolution of the relationship between project management and knowledge management: a bibliometric study. Gestão \&

Produção, SciELO Brasil, v. 25, n. 2, p. 354-369, 2017.

VASCONCELOS, I. F. F. G. d.; CYRINO, A. B.; PRALLON, E. P. et al. Resiliência organizacional e inovação sustentável: um estudo sobre o modelo de gestão de pessoas de uma empresa brasileira de energia. Cadernos Ebape. Br, SciELO Brasil, v. 13, n. 4, p. 910-929, 2015.

ZABOTTO, M. A. C.; ALVES, A. G. Formulation and monitoring of strategic plans in a public university: an analysis based on strategy as practice. Gestão $\boldsymbol{\&}$ Produção, SciELO Brasil, v. 26, n. 2, p. 2546, 2019. 